\title{
Cultivation of Students' Music Humanities Exploration Ability in Piano Teaching
}

\author{
Lijuan Li, Weiyi Hao, Yun Jing \\ Xingtai University, Xingtai, 054001, China
}

Keywords: Piano teaching, Music humanities exploration ability, Cultivation methods

\begin{abstract}
With the continuous improvement of educational system in our country, the traditional score-orientated teaching in piano teaching cannot satisfy the students' needs. The cultivation of students' music humanities exploration ability, which not only enhances the students' piano exploration ability but also ensures the students' understanding over piano knowledge, is vitally important in the overall piano teaching. Therefore, the following discussions are made on the cultivation of students' music humanities exploration ability during piano teaching in this paper.
\end{abstract}

\section{Introduction}

As the "nobility" among musical instruments, the piano has been favored by a growing number of people because of its unique artistic style and musical charm. In the past piano teaching, as affected by the traditional teaching pattern in our country, the students' day-to-day learning was often dominated by "teaching" by the teachers, without getting their exploration ability trained, so the students lacked the necessary learning motivation during in the course of study, which directly influenced the students' academic records. However, cultivating the students' music humanities exploration ability, which enables the students to independently explore the piano music in their daily study, not only enhances the students' own ability of thinking but also strengthens the cultivation of the students' innovation ability so as to improve their musicianship and aesthetic judgment. Therefore, this paper makes the following analyses on relevant paths and improvement measures in cultivation of students' music humanities exploration ability in piano teaching based on the importance of music humanistic thought exploration ability, the feasibility of students' music humanities exploration ability in piano teaching as well as the cultivating methods for students' music humanities exploration ability in piano teaching:

\section{Importance of music humanistic thought exploration ability}

Among the overall teaching activities, the difference between music teaching and other teaching activities is that the music teaching has its specific purpose, so the music talents are different in the schools with different natures. For example, general conservatories of music pay attention to cultivating the students' specialized music performance while the normal universities and colleges pay attention to cultivating the music teaching staff for elementary and secondary schools so that the students can have good piano accompaniment skills and piano teaching ability; meanwhile, the piano teaching in normal universities and colleges shall not only have their own characteristics of normal universities and colleges but also need to cultivate the students' comprehensive quality, artistic aesthetic ability and musicianship so that the students can combine the piano teaching theory and practice perfectly, which lays a solid foundation for their future teaching career.

In the traditional piano teaching, most teachers put the key teaching points on the diffusion of musical knowledge and the students' learning of musical skills, directly neglecting cultures other than music. However, in the actual application, any type of music is a specific cultural product, which is closely related to cultures, so music will be in an illusory state both in form and technically without cultures, let alone the artistic charm and aesthetic judgment of music. In other words, in the development of music, music and cultures are inseparably related with each other, so superb music skills are far from being enough. Without rather high cultural attainment, one's music learning can only be improved technically, without music imagination power and comprehension ability. New 
requirements for music teaching are proposed because of this. The teachers should not only impart musical knowledge and skills to the students but also combine the music with cultures sufficiently so that the students can get their initiative exploration ability cultivated, which will realize the aim of cultivating the students' comprehensive humanistic quality.

\section{Feasibility of students' music humanities exploration ability in piano teaching}

In the piano teaching, certain specialized knowledge and basis are needed to cultivate the students' exploration ability so that the teachers can give guidance by utilizing the students' specialized knowledge in the piano teaching and the students can independent explore piano knowledge in their future study. The analyses on the feasibility of students' music humanities exploration ability in piano teaching are mainly embodied in the aspects below:

\section{The integrated specialized knowledge structure and analytical skills}

Since the integrated specialized knowledge structure and analytical skills are the basic premises for the students to independently explore piano music, the students can grasp the orientations of exploration in their actual studies only when they have complete specialized knowledge. At the same time, the mastering of analytical skills is directly related to whether the students can analyze and understand the musical data well. Thus it can be seen that the students must have certain specialized knowledge structure and analytical skills in the process of cultivating their exploration ability.

\section{Making use of modern, advanced and rapid information acquisition methods}

With the rapid development of science and technology, the students can not only obtain musical knowledge on books, but also to acquire musical information the first time through audio-visual materials, art galleries and internet so as to pave the way for improving their music accomplishment and comprehensive ability.

\section{Cultivating methods for students' music humanities exploration ability in piano teaching}

In piano teaching, the students' music humanities exploration ability cannot be formed overnight but be cultivated for a long time. The course of cultivation cannot be separated from the teachers' guidance and the students' efforts. The cultivation of the students' humanistic exploration ability mainly covers the following paths:

\section{To innovate the teaching concept, change the teaching pattern and the cultivate exploration talents}

In the current piano teaching in our country, under the influence of traditional teaching pattern in our country, the teachers pay more attention to the students' technical training without paying attention to the expression of artistic emotions. With the continuous improvement of educational system, the students' music accomplishment and artistic aesthetics are effectively emphasized, so, in piano teaching, it is the teachers' teaching target to cultivate comprehensive music talents and the piano teaching also has been changed from the traditional playing ability and difficulty in tracks into the understanding and exploration of music, all of which laid a foundation for the cultivation of students' music humanities exploration ability.

For the cultivation of exploration piano talents, the core is to change the key point for education from the traditional "teaching" to the "guidance" so that the students can fully understand the piano arts based on obtaining specialized skills and can further explore arts while having their own artistic awareness improved. As the saying goes, "Give a man a fish and you feed him for a day. Teach him how to fish and you feed him for a lifetime." Therefore, to cultivate the students' exploration ability will not only stimulate the students' piano learning enthusiasm but also make them to engage in the future music explorations wholeheartedly. During actual cultivation, as an ability to adapt to certain learning activities, the exploration ability, which appears in the form of a type of comprehensive ability, demands that a student has a certain knowledge structure and the ability of thinking, learning 
ability, analytical ability etc. The teachers, who want to cultivate the students' exploration ability from the root in piano teaching, must cultivate the students in all aspects by combining with their actual conditions. Meanwhile, the teachers should break the traditional piano teaching concept, innovate teaching concepts by combining with the actual development conditions of piano as well as the students' actual learning abilities and cultivate the students' ability of thinking, analytical ability and exploration ability in the premise of cultivating the students' piano diathesis and aesthetic judgment. Besides, piano music is a type of art, so its unique artistic charm cannot be embodied while being taught by the teachers but be appreciated by the students after deep understanding. In the past piano teaching, there was only a single teaching pattern, where the teachers taught while the students listen all the time. This pattern directly influenced the learning effect. In the course of cultivating the students' music humanities exploration ability, such teaching pattern must be broken, because flexible teaching patterns can not only invigorate the classroom but also stimulate the students' enthusiasm in music learning to make them feel the unique charm of art, which will play an vitally important role in their future learning.

\section{To optimize the curriculum setting and strengthen music humanistic teaching}

In the piano music teaching of this new era, the teachers are supposed to implement the interrelated and interpenetrating structural system principle of piano music teaching courses of taking music aesthetics as the leader, musical expression as the carrier, musical creation and culture as the two wings and music education as the foundation with varied emphases. As a sound culture, music has been bringing endless artistic enjoyment to people with its unique artistic charm since it was formed; as an important part of human's culture, the development of music cannot be separated from cultures. In other words, as a form and carrier of human culture, music can give full play to its artistic charm and aesthetical effect on the big background of cultures. The humanity attribute of music also shows music's physical sound, psychological feeling, cultural understanding and social function etc., which require the teachers to optimize the curriculum setting fundamentally in piano teaching and to construct the diversified musical culture by combining with the current big background of humanity culture and combining with the nations, history, custom, native culture, geological knowledge and all the other aspects of piano music based on our country's traditional music. At the same time, while strengthening the music humanity teaching, the setting of curriculum optimization must take the students' actual learning conditions as the preconditions to highlight the key teaching point of piano as the core so that the students can actively explore the problems in music learning through their own music knowledge in their daily learning and can also put forward and analyze their own opinions and perspectives based on the actual development condition of music.

\section{To add the piano literature course and guide the students to deeply explore the piano music rheology}

The piano literature course added mainly includes the aspects below: Firstly, the teachers will guide the students to correctly grasp the styles of works via the piano literature course. Since the piano art has been developed for hundreds of years, the composers of the past generations have left the classic piano literature as vast as the open sea. The composers in different periods and nations had different humanistic thoughts, aesthetical concepts, composition techniques etc. and some of them even were widely divergent, so they all formed their own complete theoretical systems, styles and genres. Therefore, deep understanding of a composer's style of works is critical to correctly express the connotation of a piece of works. Studies on piano literature can help the students to fully grasp the overall context of piano music development and the students can also get perceptual experience by listening to and studying all kinds of piano literature works of different styles. Compare the time styles of works by different composers, learn the individual characteristics of their works on the background of generality creation, grasp the vertical and horizontal relationship among works and do up relevant musical information by achieving mastery so as to have an all-around three-dimensional concept for the historical development of piano music styles and to truly command the measures of performance styles of works in different periods. Excellent piano literature can provide the players with correct guidance and suggestions on playing works of such style to gradually cultivate the 
students' ability of playing musical works of different styles and to establish a correct style concept. Secondly, the teachers will actively guide the students' understanding of piano works by combining with relevant contents in the piano literature course. Piano literature, which is a unique pattern of manifestation for the creative ideas of composers, not only integrates the composer's quintessence of thought but also covers the independent artistic charm of piano, so to cultivate the students' ability of studying piano literature will not only point out the research directions of music connotation for the students but also help the students to further explore the composers' conceptions as well as the context of music development. Besides, the setting of piano literature course can help the students to accumulate more piano knowledge, expand their music horizon, even help them to further understand the composers' aesthetical thoughts and to correctly interpret the inner beauty of piano music so that the students can give full play to the emotion of a composer during piano playing for resonance with the audience. Finally, to set corresponding piano literature course can give correct guidance over the students' timbre art. Piano music is a unique sound art with different timbres reflecting different styles and characteristics of piano music works and such timbres have vitally important significance in music genres and artistic characteristics. It thus shows that it is required to integrate the culture of piano works into the learning, teaching and playing of piano so as to reach the emotional resonance between the player and composer. In the course of realizing such resonance, the setting of literature curriculum plays an active role. Through corresponding literature study, the player can correctly understand and command the music features of piano art in its different development periods. Meanwhile, by comparing the music works in different periods, the player can not only understand the styles and artistic features of piano works in specified periods but also explore the key factors for different timbres so that the player can choose a timbre style, which is the closest to the piano culture in the period of the composer, to show the works with the most beautiful timbre, which is close to the content, thought and feeling of works.

\section{Conclusion}

To sum up, in piano music teaching, the cultivation of students' music humanities exploration ability requires the teachers to combine with the students' actual learning conditions and guide them through corresponding ways in the premise of their existing knowledge structures so that the students can not only independently explore, analyze and think in daily studies to enhance their own musicianship but also improve their comprehensive music ability to lay a solid foundation for their future development.

\section{References}

[1] Yang Peihong. Brief Analysis on College Teachers' Piano Teaching Characteristics'. Journal of Qiqihar University (Philosophy and Social Science Edition), 2009, (04).

[2] Li Xiaoying. First Exploration on College Teachers' Piano Teaching'. Journal of Normal Specialised Postsecondary College, 2011, (02).

[3] Liu Qun. Brief Discussion on College Teachers' Piano Teaching'. Journal of Changshu College, 2008, (04).

[4] Gu Gengzhong. Discussion on Reforms in the College Teachers' Piano Teaching'. Journal of Yancheng Teachers'University (Philosophy and Social Science Edition), 2007, (01).

[5] Xiong Rujing. Innovation ad Practice - Brief Analysis on Reforms in the College Teachers' Piano Teaching'. Piano Art, 2012, (05).

[6] Chen Lunwang. Analysis on Phenomenon of the College Teachers' Wrong Piano Teaching'. Journal of Changchun Normal University, 2011, (07).

[7] Tao Cheng. Thought on Some Problems in College Teacher's Piano Teaching'. Journal of Anhui Normal University (Humanistic and Social Science Edition), 2011, (04). 
[8] Ding Dashui. The Educators shall Accept Good Education First - Talks about the College Teachers’ Piano Teaching'. China Music Education, 2009, (09).

[9] Liu Dongmei. How Can the College Teachers Deal with the Relationship between Techniques and Arts'. Journal of Tangshan Teachers University, 2011, (01). 